\title{
Effect of Soil Physical Conditions on Emission of Allyl Isothiocyanate and Subsequent Microbial Inhibition in Response to Brassicaceae Seed Meal Amendment
}

\author{
Likun Wang ${ }^{1}$ and Mark Mazzola ${ }^{2, \dagger}$ \\ ${ }^{1}$ Department of Plant Pathology, Washington State University, Pullman, WA 99164; and ${ }^{2}$ Tree Fruit Research Laboratory, U.S. \\ Department of Agriculture Agricultural Research Service, Wenatchee, WA 98801
}

\begin{abstract}
Generation of allyl isothiocyanate (AITC) in soil treated with residues of specific Brassicaceae species yields direct and indirect suppression of soilborne plant pathogens. Soil physical conditions demonstrably affected the quantity of AITC generated in response to soil incorporation of a Brassica juncea/Sinapis alba seed meal (SM) formulation. The concentration of AITC generated in SM-amended soil increased with an increase in temperature from 10 to $30^{\circ} \mathrm{C}$. AITC emission was also elevated with an increase in soil water potential from $-1,000 \mathrm{kPa}$ through $-40 \mathrm{kPa}$; however, a significant decrease in AITC emission was observed in a saturated soil environment $(0 \mathrm{kPa})$. Peak AITC emission was obtained 2 to $3 \mathrm{~h}$ after SM amendment under optimal conditions but the peak was delayed in soils incubated at low temperature or in extreme moisture environments. Although AITC production varied significantly across different orchard soils, all three orchard soils

Mycelial growth inhibition in fungi and oomycetes isolated from apple roots was dependent on both AITC concentration and exposure time. Pythium ultimum exhibited sensitivity to AITC at concentrations ranging from 0.01 to $0.22 \mu \mathrm{g} \mathrm{g}^{-1}$ of soil, whereas Hypocrea lixii was insensitive to AITC. Exposure to AITC at a concentration of $0.22 \mu \mathrm{g} \mathrm{g}^{-1}$ of soil for a period of $2 \mathrm{~h}$ restricted hyphal growth of Rhizoctonia solani AG-5, Ilyonectria destructans, and Mortierella alpina. $R$. solani AG-5 exhibited significant growth inhibition when incubated at AITC concentrations of 0.008 to $0.011 \mu \mathrm{g} \mathrm{g}^{-1}$ of soil for $10 \mathrm{~h}$. These findings provide information that will be useful in the management of appropriate soil variables to obtain optimal yields of AITC in response to SM soil amendments and indicate that a standard soil moisture prescription may be suitable for use when applying this SM formulation for soilborne disease control.
\end{abstract} yielded the same pattern of AITC release in response to SM amendment over the spectrum of soil water potentials examined in this study.

Keyword: tree fruits.

Preplant soil fumigation is the primary soilborne disease control measure used in high-value crop production systems, including nursery stock, tree fruit, potato, strawberry, and tomato. Although they commonly provide effective soilborne disease control, soil fumigants possess shortcomings that may limit their suitability for use in particular environments, such as organic production systems (Mazzola et al. 2015). Despite the development of technologies that aim to minimize emission of fumigant chemistries (Gao et al. 2011), application of fumigants continues to undergo stringent regulation (U.S. Environmental Protection Agency 2012). In addition, rapid recovery of pathogen populations in fumigated orchard soils (Mazzola and Manici 2012) may contribute to the relatively short-term benefit of this management approach observed in perennial cropping systems (Auvil et al. 2011). Similarly, modifications to the apple rhizosphere microbiome in response to soil fumigation appear limited in duration, with its composition in fumigated replant orchard soil indistinguishable from nontreated soil after two growing seasons (Mazzola et al. 2015).

Persistent changes in the microbiome stimulated by organic soil amendments may enable prolonged suppression of soilborne pathogens relative to that attained in response to fumigation (Mazzola et al. 2015). Soil incorporation of specific plant residues induces

${ }^{\dagger}$ Corresponding author: M. Mazzola; E-mail: mark.mazzola@ars.usda.gov

Funding: This work was supported by funds provided through the U.S. Department of Agriculture National Institute of Food and Agriculture, under award numbers 2012-51102-20294 and 2016-51102-25815.

The author(s) declare no conflict of interest.

Accepted for publication 6 October 2018.

This article is in the public domain and not copyrightable. It may be freely reprinted with customary crediting of the source. The American Phytopathological Society, 2019. modification of the soil microbial community in a manner that can result in long-term soilborne disease suppression (Cohen et al 2005; Kirkegaard and Sarwar 1998; Wiggins and Kinkel 2005a, b). A diversity of residues from plants within the Brassicaceae family have been examined for the potential to control soilborne diseases when utilized as a soil amendment. Focus on the use of these residues in pest suppression has been directed by their perceived biofumigant potential resulting from the generation of various bioactive glucosinolate hydrolysis products (Kirkegaard and Sarwar 1998). Glucosinolate profiles differ qualitatively and quantitatively among Brassicaceae species, resulting in metabolic byproducts that differ in biological activity (Antonious et al. 2009). Furthermore, glucosinolate content is not uniform across plant tissue types and is present at greatest concentration in influorescences and seeds (Borek and Morra 2005; Holst and Williamson 2004). As such, generation of glucosinolate hydrolysis products is greater in response to soil incorporation of Brassicaceae seed meal (SM) relative to the same biomass of a green manure. The use of SM, a by-product of the oil extraction process, may yield a more effective and efficient alternative to the use of Brassicaceae green manures for disease management (Chung et al. 2002; Mazzola and Mullinix 2005).

SM-induced pest control is often viewed to rely predominantly on the direct biological activity of glucosinolate hydrolysis products (Popova et al. 2017); however, numerous indirect modes of action have also been demonstrated (Cohen et al. 2005; Mazzola et al. 2001; Weerakoon et al. 2012). For example, SM is a complex carbon substrate (Brabban and Edwards 1996) that when applied to soil results in selective amplification of certain rhizosphere colonizing microorganisms possessing the capacity to induce plant systemic resistance (Cohen and Mazzola 2006). Hydrolysis products, particularly isothiocyanates, may also indirectly result in disease control by modifying the soil microbiome in a manner that induces suppression of plant pathogenic organisms (Weerakoon et al. 2012). Therefore, optimization of physical factors that affect glucosinolate hydrolysis 
can potentially influence the efficacy of SM soil amendments for pest suppression both directly and indirectly.

The glucosinolate hydrolysis product allyl isothiocyanate (AITC) (Borek et al. 1995; Mazza 1984) is generated in response to soil application of Brassica juncea SM. AITC may directly suppress specific apple root pathogens that contribute to the development of apple replant disease, including Pythium spp. and Pratylenchus penetrans (Mazzola et al. 2009). The concentration of AITC emitted from organic residues varies over time during the decomposition process (Baldrian et al. 2011; Hollister et al. 2012; Mazzola and Zhao 2010). Thus, the efficacy of AITC in the control of soilborne pathogens may vary in a temporal manner after SM application.

Several factors have been shown to influence the yield of AITC generated in response to soil incorporation of $B$. juncea plant residues. For example, higher concentrations of AITC were detected in sandy loam than in clay loam soil and at higher incubation temperatures $\left(45^{\circ} \mathrm{C}\right.$ versus $\left.15^{\circ} \mathrm{C}\right)$ when shoot material was incorporated into soil (Price et al. 2005). In another study, higher AITC concentrations were obtained with cell-disrupted versus nondisrupted shoot tissue (Morra and Kirkegaard 2002). Similarly, soil incorporation of ground $B$. juncea SM processed to generate cell-level tissue disruption produced significantly greater AITC emission than the flake form possessing a lower level of cell damage (Mazzola and Zhao 2010). To our knowledge, the effects of soil physical conditions on AITC emission in response to $B$. juncea SM soil amendment have not yet been evaluated.

This study was undertaken to assess the effects of soil temperature, water potential, and texture on AITC emission in response to a $B$. juncea/Sinapis alba SM soil amendment and to assess the relative sensitivity of apple replant pathogens, and potential beneficial microorganisms, to this bioactive compound. The B. juncea/S. alba SM was employed because this formulation, but not $B$. juncea SM used alone (Mazzola and Brown 2010), effectively controls apple replant disease, resulting in yields equivalent or superior to preplant soil fumigation (Mazzola et al. 2015). Knowledge of factors influencing AITC emission from this SM formulation could be used to optimize application protocols in the field and to devise more effective and economical SM formulations. Ultimately, this information could enable the use of reduced SM application rates and improve the effectiveness of SM for long-term soilborne disease suppression in orchard systems.

\section{Materials and Methods}

Soil and SM. Soils used in this study were collected from three different orchard locations representing a variety of soil types: a commercial (GC) orchard in Manson, Washington $\left(47^{\circ} 53^{\prime} 05^{\prime \prime} \mathrm{N}\right.$, $\left.120^{\circ} 09^{\prime} 30^{\prime \prime} \mathrm{W}\right)$; Columbia View Research and Demonstration (CV) orchard near Orondo, Washington $\left(47^{\circ} 37^{\prime} 33^{\prime \prime} \mathrm{N}, 120^{\circ} 13^{\prime} 31^{\prime \prime}\right.$ W); and Washington State University Sunrise (SR) orchard near Palisades, Washington $\left(47^{\circ} 25^{\prime} 08^{\prime \prime} \mathrm{N}, 119^{\circ} 54^{\prime} 52^{\prime \prime} \mathrm{W}\right)$. The dominant soil textures at the GC, CV, and SR orchards are Chelan gravelly sandy loam, Burch loam, and Pogue fine sandy loam, respectively (Cohen et al. 2005; Mazzola 1998, 1999). All three orchards possessed elements of the apple replant disease pathogen complex, including species of Ilyonectria, Phytophthora, Pythium, Rhizoctonia, and Pratylenchus (Cohen et al. 2005; Mazzola 1998, 1999). Soil characteristics measured at the time of collection are described in Table 1. Soil water potential $\left(\Psi_{\mathrm{T}}\right)$ was measured with an MPS-6 calibrated water potential sensor (METER Environment).
SMs utilized in this study were derived from $B$. juncea 'Pacific Gold' (Brown et al. 2004) and S. alba 'Ida Gold' (Brown et al. 1997) and possessed a glucosinolate content of 176.3 and $170.8 \mu \mathrm{mol} \mathrm{g}^{-1}$, respectively. 2-Propenyl (allyl) glucosinolate represented $>99 \%$ of the total glucosinolate contained in the B. juncea $\mathrm{SM}$, whereas $p$-hydroxylbenzyl glucosinolate was dominant $(>95 \%)$ in the S. alba SM (Mazzola et al. 2007). Both types of SM were ground and passed through a sieve with a $1-\mathrm{mm}^{2}$-diameter pore size prior to mixing at a ratio of $1: 1(\mathrm{wt} / \mathrm{wt})$.

Effect of soil physical conditions on AITC release. Separate samples with $\Psi_{\mathrm{T}}$ values of $-1,000,-100,-40$, and $0 \mathrm{kPa}$ were prepared for each soil type (CV, SR, and GC). The SM formulation (B. juncea/S. alba 1:1) was then applied to soils at a rate of 2.2 $\mathrm{t} \mathrm{ha}^{-1}$. After thorough mixing, $250 \mathrm{~g}$ of soil was sealed in mason jars (0.946-liter volume) and incubated for $25 \mathrm{~h}$ in controlled environment growth chambers (Environmental Growth Chambers) at a temperature of 10,20 , or $30^{\circ} \mathrm{C}$, with three replicate jars per soil moisture treatment per temperature. It is recommended that SM application be conducted in summer or autumn prior to tree planting in spring of the following year (Mazzola et al. 2015). Therefore, experimental temperatures were based on orchard soil temperatures for central Washington State (https://weather.wsu.edu/?p=88650) during this seasonal period (September to October).

AITC release from soil was measured using jar tops fitted with a rubber septum from which headspace volatiles were sampled with a 3.8-cm-long, 18-gauge needle. A 1-ml volume of air was extracted from the headspace and injected into a Hewlett-Packard 5880A series gas chromatograph using conditions described previously to monitor AITC release from soil (Mazzola et al. 2007). A stock solution of AITC (95\%; Sigma-Aldrich) internal standard was prepared by dissolving $2.06 \mu \mathrm{l}$ of AITC in $1 \mathrm{ml}$ of methanol, with a final concentration of $2 \mu \mathrm{g} \mu \mathrm{l}^{-1}$. The AITC solution is stable for at least 1 month when stored at $4^{\circ} \mathrm{C}$ (Borek et al. 1995). The stock solution was then diluted 1:10, and $1 \mu \mathrm{l}$ of the diluted AITC solution was injected into the gas chromatograph as the standard sample. The headspace AITC concentration was determined $30 \mathrm{~min}$ after the start of the incubation period (mason jars sealed). Following the initial sampling, AITC release was measured every hour over a 9-h period, with a final measure taken $25 \mathrm{~h}$ after SM application. The experiment was conducted twice.

Effect of SM application rate on AITC release. AITC emission from soil in response to the SM amendment rate was evaluated in GC soil. The SM formulation (B. juncea/S. alba 1:1) was applied to GC orchard soil at rates of 2.2, 4.4, and $6.6 \mathrm{tha}^{-1}$. Assays were conducted using the methods described above under incubation conditions of $30^{\circ} \mathrm{C}$ and a $\Psi_{\mathrm{T}}$ of $-40 \mathrm{kPa}$.

Sensitivity of fungi and oomycetes to AITC. Sensitivity of individual fungal and oomycete isolates to AITC emitted from the $B$. juncea/S. alba 1:1 amended soil was evaluated in vitro. These isolates were originally recovered from the roots of apple trees cultivated in replant orchard soils (Mazzola 1998). The effects of AITC concentration and duration of the exposure period on hyphal growth were evaluated separately under two experimental conditions. The effect of AITC concentration on hyphal growth was analyzed by exposing isolates to the SR orchard soil ( $\Psi_{\mathrm{T}}$ of $\left.-40 \mathrm{kPa}\right)$ amended with the $\mathrm{SM}$ formulation at a rate of $2.2 \mathrm{tha}^{-1}$. Potato dextrose agar (onefifth strength) plugs (0.5-cm diameter) colonized by $R$. solani AG-5 (isolate 1007), Pythium ultimum (isolate 1205), H. lixii (isolate B373), Mortierella alpina (isolate 001), and I. destructans (isolate 1189)

Table 1. Soil nutrient content and moisture conditions at the time of orchard soil collection

\begin{tabular}{|c|c|c|c|c|c|c|c|}
\hline Orchard soila & Soil texture & pH & $\begin{array}{c}\text { Nitrogen } \\
\left(\mathrm{mg} \mathrm{kg}^{-1}\right)\end{array}$ & $\begin{array}{l}\text { Phosphorous } \\
\left(\mathrm{mg} \mathrm{kg}^{-1}\right)\end{array}$ & $\begin{array}{c}\text { Sulfur } \\
\left(\mathrm{mg} \mathrm{kg}^{-1}\right)\end{array}$ & $\begin{array}{c}\text { Organic matter } \\
\text { content }(\%)\end{array}$ & $\begin{array}{c}\text { Water potential } \\
(\mathbf{k P a})\end{array}$ \\
\hline GC & Chelan gravelly sandy loam & 4.8 & 11 & 124 & 30 & 4.2 & -209 \\
\hline SR & Pogue fine sandy loam & 6.9 & 55 & 36 & 15 & 1.2 & -92 \\
\hline $\mathrm{CV}$ & Burch loam & 6.8 & 19 & 32 & 4 & 2.1 & -63 \\
\hline
\end{tabular}

${ }^{\mathrm{a}} \mathrm{GC}=$ commercial orchard, $\mathrm{SR}=$ Sunrise orchard, and CV = Columbia View Research and Demonstration orchard in Washington State. 
were sealed in a 4- $\mu \mathrm{m}$ pore diameter mesh bag and incubated in mason jars containing SM-treated soil for a 2 -h exposure period ( 0 to 2 , 2 to 4,4 to 6,6 to 8,8 to 10 , and 24 to $26 \mathrm{~h}$ after SM amendment) at $30^{\circ} \mathrm{C}$. For $R$. solani AG-5, agar plugs containing sclerotia were used.
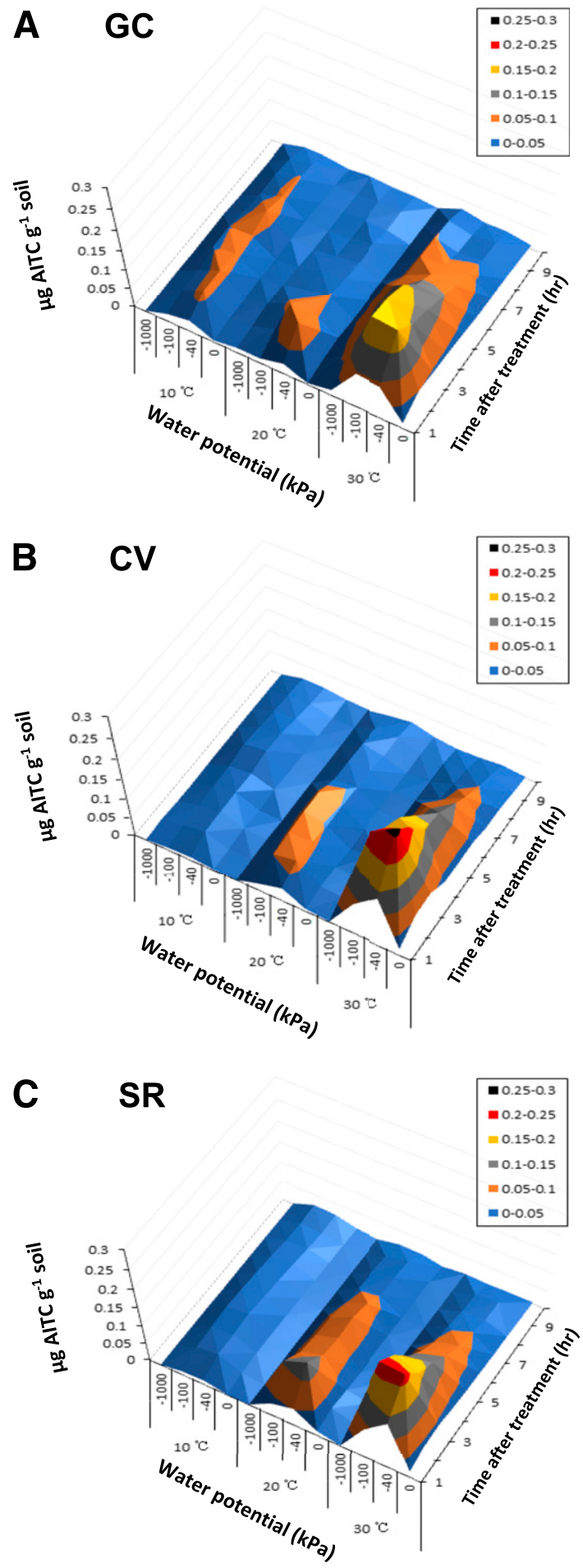

Fig. 1. Allyl isothiocyanate (AITC) emission from A, commercial (GC) orchard, B, Columbia View Research and Demonstration (CV) orchard, and C, Washington State University Sunrise (SR) orchard soils. Soil was amended with Brassica juncea/Sinapis alba 1:1 seed meal at a rate of $2.2 \mathrm{t} \mathrm{ha}^{-1}$ and incubated in 0.946liter mason jars at water potentials of $-1,000,-100,-40$, and $0 \mathrm{kPa}$ and temperatures of 10,20 , and $30^{\circ} \mathrm{C}$, with three replicates for each treatment. The AITC concentration was determined by monitoring volatiles in the mason jar headspace by gas chromatography.
Three replications were tested for each fungus or oomycete isolate per 2-h AITC exposure period, in which the AITC concentration in the headspace of the jar was determined as previously described. Following incubation, agar plugs were retrieved from the mason jar and immediately placed on freshly prepared water agar amended with ampicillin $\left(100 \mu \mathrm{g} \mathrm{ml}^{-1}\right)$ in a 9-cm-diameter Petri dish, along with non-AITC-exposed agar plugs (control) of the same isolate. The cultures were incubated at room temperature and relative hyphal extension was measured every $24 \mathrm{~h}$ until growth of the control culture extended to the edge of the agar plate. The duration of the assessment period ranged from 72 to $144 \mathrm{~h}$ depending on the growth rate of the isolate. Growth inhibition in response to AITC exposure was determined using the following formula: Growth inhibition $=1-$ (hyphal growth of the AITC-exposed culture/hyphal growth of the nonexposed culture) $\times 100$.

The effect of the AITC exposure period on hyphal growth was conducted using the same soils and conditions as described above, with the exception of soil moisture, which was maintained at a $\Psi_{\mathrm{T}}$ of $-1,000 \mathrm{kPa}$. Mesh bags containing agar plugs of the experimental fungal or oomycete isolates were incubated in mason jars with the SM-amended soil for different time spans, which ranged from 0,2 , $4,6,8$, and $10 \mathrm{~h}$ posttreatment. The AITC concentration in the headspace of the jar was measured every $2 \mathrm{~h}$ until the tenth hour, which was maintained at a relatively consistent level $\left(0.008\right.$ to $0.011 \mu \mathrm{g} \mathrm{g}^{-1}$ of soil) over the duration of the exposure period.

Data analysis. Statistical analyses were conducted using SAS version 9.4 software. The measurements of AITC concentration over time were analyzed using the SAS general linear model (GLM) for repeated-measures design. Hyphal growth inhibition relative to the control at the initial and final observation times was analyzed individually using the SAS GLM model for a completely randomized design. Data were subjected to analysis of variance and means separation using the Fisher least significant difference test, with $P \leq 0.05$ considered significant. Hyphal growth inhibition was carried out two times with the experimental effect analyzed.

\section{Results}

Effect of soil variables on AITC production. Regardless of orchard soil, the peak AITC concentration was detected 2 to $3 \mathrm{~h}$ after SM application (Fig. 1). In extremely dry $\left(\Psi_{\mathrm{T}}\right.$ of $\left.-1,000 \mathrm{kPa}\right)$ or saturated $\left(\Psi_{\mathrm{T}}\right.$ of $\left.0 \mathrm{kPa}\right)$ soils, or at the lowest incubation temperature evaluated $\left(10^{\circ} \mathrm{C}\right)$, a period of peak AITC production was not discernable in soils from the three orchard study sites as a result of low concentrations. For example, when SM was applied at a rate of $2.2 \mathrm{t} \mathrm{ha}^{-1}$ to SR soil incubated at $30^{\circ} \mathrm{C}$ and a $\Psi_{\mathrm{T}}$ of $-1,000 \mathrm{kPa}$, peak AITC emission lagged until 4 to $5 \mathrm{~h}$ postapplication and was detected at low concentrations ( 0.001 to $0.014 \mu \mathrm{g} \mathrm{g}^{-1}$ of soil; Fig. 1C). In soils amended with SM at $6.6 \mathrm{t} \mathrm{ha}^{-1}$, the AITC concentration decreased with time to a level at $25 \mathrm{~h}$ posttreatment that approached that of the peak concentration detected in SM 2.2 and $4.4 \mathrm{tha}^{-1}$ at $2 \mathrm{~h}$ after SM application.

Soil temperature $(P<0.001)$, moisture $(P<0.001)$, and texture $(P<0.001)$ had significant effects on AITC concentration. There were also significant interactions between temperature and water potential $(P<0.001)$, water potential and texture $(P<0.001)$, and temperature and texture $(P<0.001)$. AITC production increased with an increase in soil temperature from 10 to $30^{\circ} \mathrm{C}$. In assays conducted in soil at a $\Psi_{\mathrm{T}}$ of $-1,000 \mathrm{kPa}$, the effect of temperature on AITC emission was not distinct $(P=0.273)$. The AITC concentration generally increased with an increase in soil water potential; however, a significant decrease $(P \leq 0.006)$ in AITC generation was observed when the soil was very dry or saturated relative to that detected at $\Psi_{\mathrm{T}}$ levels of -100 and $-40 \mathrm{kPa}$ (Fig. 1).

In soils applied with $2.2 \mathrm{tha}^{-1} \mathrm{SM}$, comparing among the soil textures, the greatest AITC concentration $\left(0.265 \mu \mathrm{g} \mathrm{g}^{-1}\right.$ of soil) was recorded in Burch loam soil (CV orchard) when incubated at $30^{\circ} \mathrm{C}$ and $-40 \mathrm{kPa}$ for $2 \mathrm{~h}$ (Fig. 1B). However, when incubated at $20^{\circ} \mathrm{C}$ and $-40 \mathrm{kPa}$ for $2 \mathrm{~h}$, the greatest AITC concentration $\left(0.131 \mu \mathrm{g} \mathrm{g}^{-1}\right.$ of soil) among the three soil textures was recorded in Pogue fine sandy loam (SR orchard) soil (Fig. 1C). Additionally, there was no 
significant difference ( $P=0.501$ and $P=0.625$, respectively) in the peak AITC concentration observed between $\Psi_{\mathrm{T}}$ levels of -100 and $-40 \mathrm{kPa}$ in assays conducted in the GC or SR soils (Fig. 1, A and C), whereas a significant difference $(P=0.002)$ was observed in the CV soil between these two water potential levels (Fig. 1B).

Effect of SM application rate on AITC production. The SM application rate had a significant $(P<0.001)$ effect on AITC production. When GC soil was incubated at $30^{\circ} \mathrm{C}$ and a $\Psi_{\mathrm{T}}$ of $-40 \mathrm{kPa}$, the AITC concentration at $2 \mathrm{~h}$ after soil treatment was 0.189 , 0.231 , and $0.558 \mu \mathrm{g} \mathrm{g}^{-1}$ of soil in soil amended with $\mathrm{SM}$ at 2.2, 4.4, and $6.6 \mathrm{t} \mathrm{ha}^{-1}$, respectively (Fig. 2). AITC emission increased with an increasing SM amendment rate (Fig. 2); however, the change in concentration did not demonstrate a linear response, as can be observed from the dramatic increase in peak AITC concentration when the SM rate was elevated from 4.4 to $6.6 \mathrm{t} \mathrm{ha}^{-1}$ (Fig. 2).

Sensitivity of fungi and oomycetes to AITC. Fungi and oomycetes differed in sensitivity to AITC depending on the concentration (Fig. 3) as well as the duration of the exposure period (Fig. 4). Once removed from the AITC environment, isolates differed in recovery as evidenced by relative growth inhibition recorded at the initial (Fig. 3A) and final (Fig. 3B) assessment periods. Pythium ultimum exhibited the greatest sensitivity to AITC among the isolates examined, with growth on water agar significantly restricted (i.e., time after SM treatment) regardless of the AITC concentration to which it had been exposed (Fig. 3). Pythium ultimum was the only fungus or oomycete exhibiting no resumption of growth at the initial growth assessment $(24 \mathrm{~h})$, regardless of AITC concentration (Fig. 3A). In addition, the Pythium ultimum culture exposed to AITC was the only test isolate that continued to exhibit significant growth reduction relative to the nonexposed culture after 72-h incubation on water agar regardless of AITC concentration (Fig. 3B). By comparison, resumption of $H$. lixii growth was delayed $24 \mathrm{~h}$ on water agar after exposure to AITC at a concentration above $0.01 \mu \mathrm{g} \mathrm{g}^{-1}$ of soil (Fig. 3A); however, after 96-h incubation, H. lixii hyphal growth was similar for AITC-exposed and nonexposed cultures (Fig. 3B). I. destructans, M. alpina, and $R$. solani AG-5 demonstrated similar levels of sensitivity to AITC. All isolates exposed to AITC for $2 \mathrm{~h}$ at a concentration of $0.05 \mu \mathrm{g} \mathrm{g}^{-1}$ of soil or greater exhibited significant growth reduction after $24 \mathrm{~h}$ incubation on water agar (Fig. 3A). However, at the final assessment period (96 or $144 \mathrm{~h}$ ), a significant reduction in relative hyphal growth was only observed for cultures exposed to AITC at a concentration of $0.22 \mu \mathrm{g} \mathrm{g}^{-1}$ of soil (Fig. 3B).

The effect of the duration of exposure to AITC on hyphal growth inhibition was assessed under conditions that maintained a relatively constant AITC concentration of 0.008 to $0.011 \mu \mathrm{g} \mathrm{g}^{-1}$ of soil (Fig. 4). At the AITC concentration generated in this assay, growth of I. destructans, H. lixii, and M. alpina on water agar was not significantly inhibited irrespective of the duration of exposure (Fig. 4). Hyphal growth of Pythium ultimum on water agar was not significantly

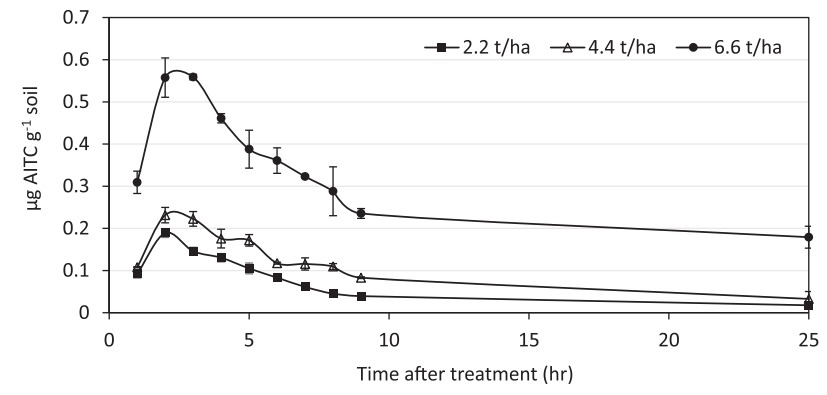

Fig. 2. Temporal emission of allyl isothiocyanate (AITC) from the commercial (GC) orchard soil amended with the Brassica juncea/Sinapis alba 1:1 seed meal formulation at a rate of $2.2,4.4$, or $6.6 \mathrm{tha}^{-1}$. Soils were incubated at $30^{\circ} \mathrm{C}$ and a water potential of $-40 \mathrm{kPa}$. The AITC concentration was determined by monitoring volatiles in the headspace of a 0.946 -liter mason jar by gas chromatography. Each data point represents the standard error of the mean $(n=3)$.

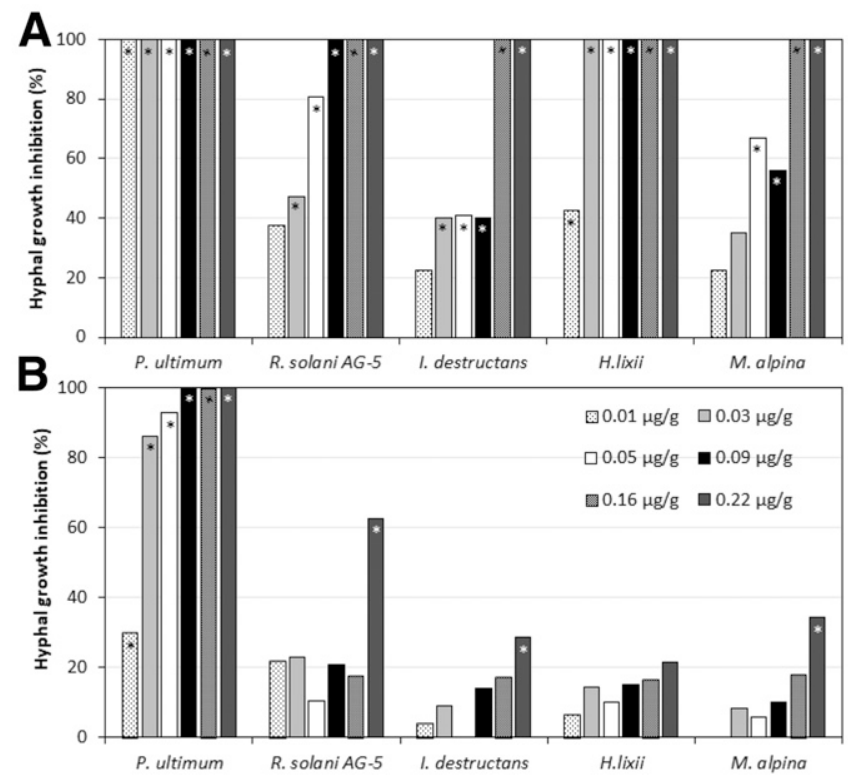

Fig. 3. Relative inhibition of Pythium ultimum, Rhizoctonia solani AG-5, Ilyonectria destructans, Hypocrea lixii, and Mortierella alpina hyphal growth on water agar after a 2-h exposure period to allyl isothiocyanate (AITC) emitted from Brassica juncea: Sinapis alba 1:1 seed meal-amended $\left(2.2 \mathrm{t} \mathrm{ha}^{-1}\right)$ Washington State University Sunrise orchard soil incubated at $30^{\circ} \mathrm{C}$ and a water potential of $-40 \mathrm{kPa}$. The key indicates the peak AITC concentrations (from lowest to highest) during the exposure periods of 24 to 26,8 to 10,6 to 8,4 to 6,2 to 4 , and 0 to $2 \mathrm{~h}$ posttreatment, respectively. A, Initial growth assessment on water agar was conducted at $24 \mathrm{~h}$. B, Timing of the final growth assessment varied depending on isolate growth rate $(72 \mathrm{~h}$ for Pythium ultimum, $96 \mathrm{~h}$ for $R$. solani AG-5 and $\mathrm{H}$. lixii, or $144 \mathrm{~h}$ for $I$. destructans and $M$. alpina). Data bars designated with an asterisk denote hyphal growth significantly $(P \leq 0.05)$ inhibited by AITC.
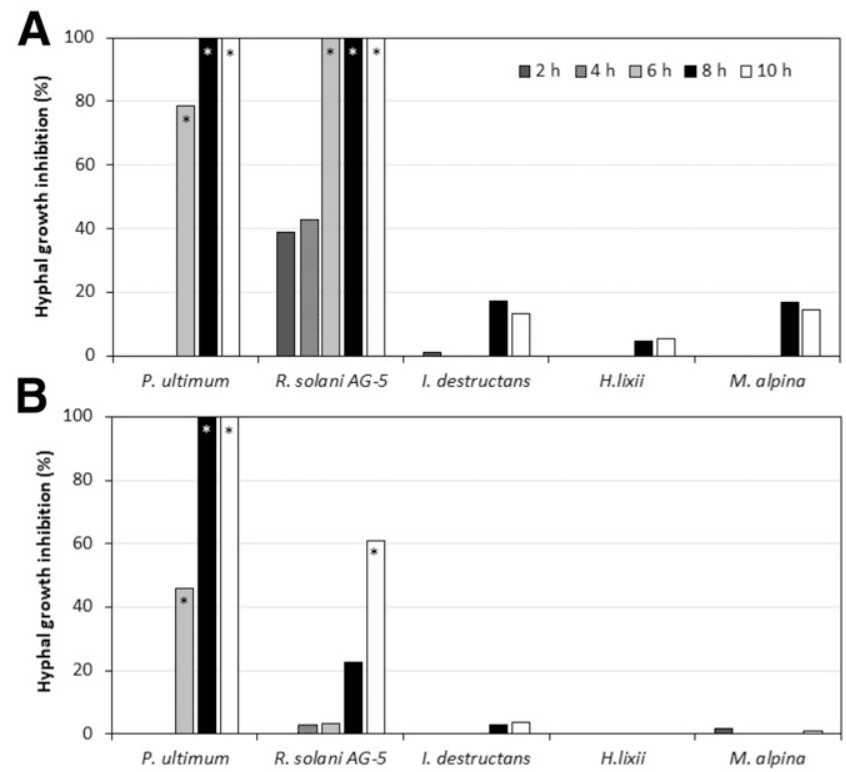

Fig. 4. Relative inhibition of Pythium ultimum, Rhizoctonia solani AG-5, Ilyonectria destructans, Hypocrea lixii, and Mortierella alpina hyphal growth on water agar after exposure to allyl isothiocyanate (AITC) emitted from Brassica juncea/Sinapis alba 1:1 seed meal-amended $\left(2.2 \mathrm{t} \mathrm{ha}^{-1}\right)$ Washington State University Sunrise orchard soil at $30^{\circ} \mathrm{C}$ and a water potential of $-1,000 \mathrm{kPa}$. The key indicates the duration of the exposure periods. An AITC concentration level of 0.008 to $0.011 \mu \mathrm{g} \mathrm{g}^{-1}$ was maintained during the exposure period. A, Initial growth assessment on water agar was conducted at $24 \mathrm{~h}$. B, Timing of the final growth assessment varied depending on isolate growth rate (at $72 \mathrm{~h}$ for Pythium ultimum, $96 \mathrm{~h}$ for $R$. solani AG-5 and $H$. lixii, or $144 \mathrm{~h}$ for I. destructans and M. alpina). Data bars designated with an asterisk denote hyphal growth significantly $(P \leq 0.05)$ inhibited by AITC. 
inhibited after an exposure period of less than $6 \mathrm{~h}$, but growth was completely inhibited when the AITC exposure period was $8 \mathrm{~h}$ or greater (Fig. 4). R. solani AG-5 exposed to AITC for 6 to $10 \mathrm{~h}$ exhibited no growth when assessed at $24 \mathrm{~h}$ (Fig. 4A); however, when observed at $96 \mathrm{~h}$ of incubation, the fungus did not exhibit a significant reduction in hyphal growth with an AITC exposure period of less than $10 \mathrm{~h}$ (Fig. 4B).

\section{Discussion}

Soilborne disease control in response to $B$. juncea SM soil amendment is achieved through multiple mechanisms of action, including the production of AITC. Production of AITC may directly suppress disease through its fungicidal or nematicidal activity, or indirectly through its effect on transformation of the soil microbiome. The latter outcome may yield disease control through the development of soil suppressiveness (Weerakoon et al. 2012) or the induction of host defense responses (Cohen and Mazzola 2006; Cohen et al. 2005; Wang and Mazzola 2017). Much effort has gone into maximizing the generation of isothiocyanates via plant tissue disruption and using plant residues with high glucosinolate content (Morra and Kirkegaard 2002). The results of this study indicate that employing SM under optimal soil physical conditions may yield benefits beyond those attainable through increased cell disruption at a given residue input. With respect to disease control resulting from SM amendment, adjusting the seasonal timing of SM application and modifying water-management practices to enhance $B$. juncea SM-derived AITC generation is likely to have a positive effect on overall disease control.

Numerous environmental factors have potential to modulate the generation of glucosinolate hydrolysis products after soil incorporation of Brassicaceae residues. Soil $\mathrm{pH}$, temperature, and moisture were shown to influence generation of isothiocyanates in response to application of Brassicaceae leaf tissues (Price 1999). The AITC concentration in response to incorporation of $B$. juncea whole plant tissue increased with increasing temperature ranging from 15 to $45^{\circ} \mathrm{C}$ (Price et al. 2005). Comparable results were obtained in the current study with elevated AITC production detected over soil temperatures ranging from 10 to $30^{\circ} \mathrm{C}$. In the presence of sufficient moisture, AITC generation was maximal at the highest temperature examined in this study $\left(30^{\circ} \mathrm{C}\right)$. Regardless of soil temperature, maximum AITC production was observed within 2 to $3 \mathrm{~h}$ of SM amendment and declined thereafter over the course of the 25-h monitoring period. This is in contrast to the study by Price et al. (2005), in which no difference in AITC concentration was observed over time in assays conducted at $15^{\circ} \mathrm{C}$ but differences were observed when examined at 30 or $45^{\circ} \mathrm{C}$. The influence of increased temperature on yield of AITC in response to SM amendment was greater in the Burch loam (CV) and Chelan gravelly sandy loam (GC) soil than in the Pogue fine sandy loam SR orchard soil.

These findings have implications with regard to the application and integration of this disease control measure into orchard management programs. Although previous studies using vegetative $B$. juncea residues indicated that AITC generation was constant over time when conducted at low temperature (Price et al. 2005), AITC generation in the current study exhibited a time-dependent response that was consistent at all temperatures examined. This finding indicates that tarping of treated soils in the field should be conducted immediately after SM application, irrespective of soil temperature, to attain maximum retention of biologically active chemistries in the soil system. Orchard renovation generally occurs in the autumn after harvest, or more infrequently in spring, when soil temperatures in central Washington State are typically lower than $15^{\circ} \mathrm{C}$. Maximum soil temperature in this region at a depth of 8 inches is recorded in August and commonly ranges between 25 and $27^{\circ} \mathrm{C}$ (https:// weather.wsu.edu/?p=88650). Soil temperature approaching $20^{\circ} \mathrm{C}$ is experienced in May and September of the year in central Washington State and may also serve as appropriate SM treatment time periods, particularly in sandy soils, to attain effective generation of AITC.
Generation of glucosinolate hydrolysis products is reliant on the presence of sufficient free water to enable myrosinase activity (Lazzeri et al. 2004; Tyagi 2002). In a previous study, no difference in isothiocyanate generation was observed when Brassica leaf tissues were incorporated into waterlogged soil and soils at a $\Psi_{\mathrm{T}}$ of $-32 \mathrm{kPa}$ (Morra and Kirkegaard 2002). In contrast, the production of AITC in the current study was significantly reduced under extremely dry or saturated $\left(\Psi_{\mathrm{T}}\right.$ of $\left.0 \mathrm{kPa}\right)$ soil moisture conditions relative to the two moderate soil moisture $\Psi_{\mathrm{T}}$ levels of -100 and $-40 \mathrm{kPa}$. Isothiocyanates are nonwater-soluble compounds and very lipophilic (Holst and Williamson 2004); however, glucosinolates are known to be water soluble. Thus, the reduction in AITC production observed at a water potential of $0 \mathrm{kPa}$ may have resulted from the loss of glucosinolates in free soil water. In central Washington State, commercial orchard production systems rely on irrigation to maintain adequate soil moisture through the growing season. Access to irrigation water provides the opportunity to effectively manipulate soil moisture to a level that will yield effective generation of glucosinolate hydrolysis products in response to SM amendment. All three orchard soils yielded the same pattern of AITC release over the spectrum of soil water potentials examined in this study. This finding indicates that a standard soil moisture prescription may be suitable for use when applying SM soil amendment for soilborne disease control.

In general, it is perceived that sandier soil with lower organic matter content will yield greater activity of glucosinolate hydrolysis products (Matthiessen and Kirkegaard 2006). Price et al. (2005) demonstrated that AITC was released at greater levels from a sandy loam soil than a clay loam soil after incorporation of $B$. juncea whole plant tissue. This response may be attributable to slower diffusion of gasphase AITC through the smaller-pore clay soil and may also result from the reaction of AITC with organic carbon in the clay soil (Price et al. 2005). In the current study, the soil texture among these three sites ranged from a Pogue fine sandy loam (SR), which had 70 to 95\% sand, to a Burch loam (CV; $61 \%$ silt, $30 \%$ sand, and $9 \%$ clay). The soils also varied considerably in organic matter content, with the Chelan gravelly sandy loam soil having the highest $(4.2 \%)$ and Pogue fine sandy loam soil the lowest $(1.2 \%)$ organic content (Table 1). There was a distinct difference among the three orchard soils in emission of AITC following SM amendment. At the same SM application rate, AITC levels detected in the GC soil with high organic matter content were significantly lower than the CV or SR soils when assays were incubated at 20 or $30^{\circ} \mathrm{C}$. The greatest AITC production was observed in the SR sandy loam soil in assays conducted at $20^{\circ}$ but the Burch loam soil when incubated at $30^{\circ} \mathrm{C}$ with a moisture $\Psi_{\mathrm{T}}$ of $-40 \mathrm{kPa}$. Knowledge of these interacting soil factors on the yield of isothiocyanates in response to SM amendment may be instrumental in the optimization of this approach to soilborne disease management in orchard systems.

When assayed in the high organic matter GC soil, a greater increment in AITC emission was obtained by increasing the treatment rate from 4.4 to $6.6 \mathrm{t} \mathrm{ha}^{-1}$ compared with an increase in treatment rate from 2.2 to $4.4 \mathrm{tha}^{-1}$. In the GC soil with high organic matter content, this response may have resulted from saturation of organic molecule isothiocyanate-binding sites (Matthiessen et al. 1996) at some point above $4.4 \mathrm{t} \mathrm{ha}^{-1}$. If true, this would lead to the prediction that the SR and CV soils with lower organic matter content should yield higher relative increases in AITC production at the lower rates of amendment compared with those from GC soil. This prediction appears to be borne out by greater emission of AITC observed from the SR and CV $2.2 \mathrm{t} \mathrm{ha}^{-1}$ treated soils.

Products of glucosinolate hydrolysis may exert a direct inhibitory effect on a wide range of soilborne plant pathogens. Sensitivity to specific glucosinolate hydrolysis products, including volatile isothiocyanates, exists among plant pathogenic fungi and oomycetes (Manici et al. 1997; Mazzola and Zhao 2010). This may influence mechanisms of direct pathogen suppression and control of corresponding diseases. Control of apple root infection by $R$. solani AG-5 through direct activity of AITC was attained with a fineparticle, but not coarse-particle, B. juncea SM amendment. Disease control was associated with a significantly higher peak AITC level 
generated in response to the fine-particle SM than the coarse particle rather than total AITC produced over time, which did not differ among the two SM treatments (Mazzola and Zhao 2010). In the current study, growth inhibition of the AITC-sensitive isolate Pythium ultimum was obtained using a short exposure period $(2 \mathrm{~h})$ at all AITC concentrations tested. In addition, at a low AITC concentration $(0.008$ to $0.011 \mu \mathrm{g}$ $\mathrm{g}^{-1}$ ), extending the exposure period yielded effective inhibition of Pythium ultimum, indicating that growth of the AITC-sensitive pathogen was affected not only by AITC concentration but also by exposure period duration. With one exception (10 h; R. solani AG-5), extending the period of exposure at the same low AITC concentration did not increase inhibition of the moderately sensitive $R$. solani AG-5 or insensitive $I$. destructans isolate. These findings indicate that a direct growth-inhibitory biofumigant effect, and corresponding disease control, in response to SM-derived total and peak AITC yield will likely be dependent on the target pathogens.

Indirect disease suppression through amplification of specific microbial elements that antagonize or parasitize plant pathogens may also be influenced by the yield of isothiocyanates generated in response to Brassicaceae residue soil amendments (Weerakoon et al. 2012). H. lixii and M. alpina demonstrated the lowest level of AITC sensitivity among the isolates examined in this study, and Trichoderma spp. have been reported to be relatively insensitive to isothiocyanates (Galletti et al. 2008; Larkin and Griffin 2007; Mazzola and Zhao 2010). However, H. lixii (teleomorph of $T$. harzianum) exhibited a marginally greater level of insensitivity to this metabolite than did $M$. alpina. Interestingly, this slight differentiation appears to have a significant role in determining the relative dominance of these two fungi in $B$. juncea SM-amended soil and corresponding effects on disease suppression. Proliferation of Trichoderma spp. and associated development of soil suppressiveness to Pythium abappressorium was elevated when SM was applied in a manner (soil tarping) that resulted in elevated production of AITC (Weerakoon et al. 2012). When SM was applied in a manner that reduced AITC emission (no tarp), M. alpina consistently became dominant in the fungal community relative to Trichoderma spp.

In conclusion, AITC generation in response to soil incorporation of a $B$. juncea/S. alba SM formulation was affected by soil physical conditions. AITC generation following SM amendment can be improved by applying the treatment under the appropriate soil moisture conditions $\left(\Psi_{\mathrm{T}}\right.$ of -100 to $\left.-40 \mathrm{kPa}\right)$ during periods when soil temperature exceeds $20^{\circ} \mathrm{C}$. The relative sensitivity of various fungal and oomycete plant pathogens to AITC varied significantly, indicating that composition of the pathogen profile and dominance of individuals may necessitate modification of the SM application rate to attain effective control of replant disease. As observed previously, $H$. lixii was relatively insensitive to AITC, providing further evidence for the possible integration of SM amendment with use of this mycoparasite for the control of soilborne plant pathogens.

\section{Acknowledgments}

We thank T. Somera and M. F. Cohen for critical review of the manuscript.

\section{Literature Cited}

Antonious, G. F., Bomford, M., and Vincelli, P. 2009. Screening Brassica species for glucosinolate content. J. Environ. Sci. Health B 44:311-316.

Auvil, T. D., Schmidt, T. R., Hanrahan, I., Castillo, F., McFerson, J. R., and Fazio, G. 2011. Evaluation of dwarfing rootstocks in Washington apple replant sites. Acta Hortic.: 265-271.

Baldrian, P., Kolařík, M., Štursová, M., Kopecký, J., Valášková, V., Větrovský, T., Žifčáková, L., Šnajdr, J., Rídl, J., Vlček, Č., and Vořřšková, J. 2011. Active and total microbial communities in forest soil are largely different and highly stratified during decomposition. ISME J. 6:248-258.

Borek, V., and Morra, M. J. 2005. Ionic thiocyanate ( $\mathrm{SCN}-$ ) production from 4hydroxybenzyl glucosinolate contained in Sinapis alba seed meal. J. Agric. Food Chem. 53:8650-8654.

Borek, V., Morra, M. J., Brown, P. D., and McCaffrey, J. P. 1995. Transformation of the glucosinolate-derived allelochemicals allyl isothiocyanate and allylnitrile in soil. J. Agric. Food Chem. 43:1935-1940.

Brabban, A. D., and Edwards, C. 1996. Characterization of growth and product formation by a thermophilic streptomycete grown in a particulate rapemealderived liquid medium. J. Appl. Bacteriol. 80:651-658.
Brown, J., Davis, J. B., Erickson, D. A., Brown, A. P., and Seip, L. 1997. Registration of 'Ida Gold' yellow mustard. Crop Sci. 38:541.

Brown, J., Davis, J. B., Erickson, D. A., and Gosselin, T. 2004. Registration of 'Pacific Gold' oriental condiment mustard. Crop Sci. 44:2271-2272.

Chung, W. C., Huang, J. W., Huang, H. C., and Jen, J. F. 2002. Effect of ground Brassica seed meal on control of Rhizoctonia damping-off of cabbage. Can. J. Plant Pathol. 24:211-218.

Cohen, M. F., and Mazzola, M. 2006. Resident bacteria, nitric oxide emission and particle size modulate the effect of Brassica napus seed meal on disease incited by Rhizoctonia solani and Pythium spp. Plant Soil 286:75-86.

Cohen, M. F., Yamasaki, H., and Mazzola, M. 2005. Brassica napus seed meal soil amendment modifies microbial community structure, nitric oxide production and incidence of Rhizoctonia root rot. Soil Biol. Biochem. 37: 1215-1227.

Galletti, S., Sala, E., Leoni, O., Burzi, P. L., and Cerato, C. 2008. Trichoderma spp tolerance to Brassica carinata seed meal for a combined use in biofumigation. Biol. Control 45:319-327.

Gao, S., Hanson, B. D., Wang, D., Browne, G. T., Qin, R., Ajwa, H. A., and Yates, S. R. 2011. Methods evaluated to minimize emissions from preplant soil fumigation. Calif. Agric. 65:41-46.

Hollister, E. B., Hu, P., Wang, A. S., Hons, F. M., and Gentry, T. J. 2012 Differential impacts of Brassicaceous and non-Brassicaceous oil seed meals on soil bacterial and fungal communities. FEMS Microbiol. Ecol. 83: 632-641.

Holst, B., and Williamson, G. 2004. A critical review of the bioavailability of glucosinolates and related compounds. Nat. Prod. Rep. 21:425-447.

Kirkegaard, J. A., and Sarwar, M. 1998. Biofumigation potential of brassicas. Plant Soil 201:71-89.

Larkin, R. P., and Griffin, T. S. 2007. Control of soilborne potato diseases using Brassica green manures. Crop Prot. 26:1067-1077.

Lazzeri, L., Leoni, O., and Manici, L. M. 2004. Biocidal plant dried pellets for biofumigation. Ind. Crops Prod. 20:59-65.

Manici, L. M., Lazzeri, L., and Palmieri, S. 1997. In vitro fungitoxic activity of some glucosinolates and their enzyme-derived products towards plant pathogenic fungi. J. Agric. Food Chem. 45:2768-2773.

Matthiessen, J. N., Desmarchelier, J. M., Vu, L. T., and Shackleton, M. A. 1996 Comparative efficacy of fumigants against hatching whitefringed beetle (Coleoptera: Curculionidae) larvae and the sorption by soil. J. Econ. Entomol. 89:1372-1378.

Matthiessen, J. N., and Kirkegaard, J. A. 2006. Biofumigation and enhanced biodegradation: Opportunity and challenge in soilborne pest and disease management. Crit. Rev. Plant Sci. 25:235-265.

Mazza, G. 1984. Volatiles in distillates of fresh, dehydrated and freeze dried horseradish. Can. Inst. Food Sci. Technol. J. 17:18-23.

Mazzola, M. 1998. Elucidation of the microbial complex having a causal role in the development of apple replant disease in Washington. Phytopathology 88: 930-938.

Mazzola, M. 1999. Transformation of soil microbial community structure and Rhizoctonia-suppressive potential in response to apple roots. Phytopathology 89:920-927.

Mazzola, M., and Brown, J. 2010. Efficacy of brassicaceous seed meal formulations for the control of apple replant disease in conventional and organic production systems. Plant Dis. 94:835-842

Mazzola, M., Brown, J., Izzo, A. D., and Cohen, M. F. 2007. Mechanism of action and efficacy of seed meal-induced pathogen suppression differ in a Brassicaceae species and time-dependent manner. Phytopathology 97: 454-460

Mazzola, M., Brown, J., Zhao, X., Izzo, A. D., and Fazio, G. 2009. Interaction of Brassicaceous seed meal and apple rootstock on recovery of Pythium spp. and Pratylenchus penetrans from roots grown in replant soils. Plant Dis. 93: 51-57.

Mazzola, M., Granatstein, D. M., Elfving, D. C., and Mullinix, K. 2001. Suppression of specific apple root pathogens by Brassica napus seed meal amendment regardless of glucosinolate content. Phytopathology 91: 673-679

Mazzola, M., Hewavitharana, S. S., and Strauss, S. L. 2015. Brassica seed meal soil amendments transform the rhizosphere microbiome and improve apple production through resistance to pathogen reinfestation. Phytopathology 105 460-469.

Mazzola, M., and Manici, L. M. 2012. Apple replant disease: Role of microbial ecology in cause and control. Annu. Rev. Phytopathol. 50:45-65.

Mazzola, M., and Mullinix, K. 2005. Comparative field efficacy of management strategies containing Brassica napus seed meal or green manure for the management of apple replant disease. Plant Dis. 89:1207-1213.

Mazzola, M., and Zhao, X. 2010. Brassica juncea seed meal particle size influences chemistry but not soil biology-based suppression of individual agents inciting apple replant disease. Plant Soil 337:313-324.

Morra, M. J., and Kirkegaard, J. A. 2002. Isothiocyanate release from soilincorporated Brassica tissue. Soil Biol. Biochem. 34:1683-1690.

Popova, I. E., Dubie, J., and Morra, M. J. 2017. Optimization of hydrolysis conditions for release of biopesticides from glucosinolates in Brassica juncea and Sinapis alba seed meal extracts. Ind. Crops Prod. 97:354-359. 
Price, A. J. 1999. Quantification of volatile compounds produced during simulated biofumigation utilizing Indian mustard degrading in soil under different environmental conditions. M.S. thesis, University of Tennessee Department of Plant and Soil Sciences, Knoxville, TN

Price, A. J., Charron, C. S., Saxton, A. M., and Sams, C. E. 2005. Allyl isothiocyanate and carbon dioxide produced during degradation of Brassica juncea tissue in different soil conditions. HortScience 40:1734-1739.

Tyagi, A. K. 2002. Influence of water soaking of mustard cake on glucosinolate hydrolysis. Anim. Feed Sci. Technol. 99:215-219.

U.S. Environmental Protection Agency. 2012. Phase 2 site-specific fumigant management plans and post-application summaries. EPA Factsheet 735-F-12007. U.S. Environmental Protection Agency, Washington, DC.
Wang, L., and Mazzola, M. 2017. Factors affecting emission of AITC and subsequent disease control efficacy of Brassica juncea seed meal soil amendment (Abstract). Phytopathology 107(suppl):S5.46.

Weerakoon, M. D., Reardon, L. C., Paulitz, T. C., Izzo, A. D., and Mazzola, M. 2012 Long-term suppression of Pythium abappressorium induced by Brassica juncea seed meal amendment is biologically mediated. Soil Biol. Biochem. 51:44-52.

Wiggins, B. E., and Kinkel, L. L. 2005a. Green manures and crop sequences influence potato diseases and pathogen inhibitory activity of indigenous streptomycetes. Phytopathology 95:178-185.

Wiggins, B. E., and Kinkel, L. L. 2005b. Green manures and crop sequences influence alfalfa root rot and pathogen inhibitory activity among soilborne streptomycetes. Plant Soil 268:271-283. 